\title{
Seroprevalence of Toxoplasmosis in Pregnant Women Attending Antenatal Care at Sir Yahaya Memorial Hospital, Birnin Kebbi, Northwestern Nigeria
}

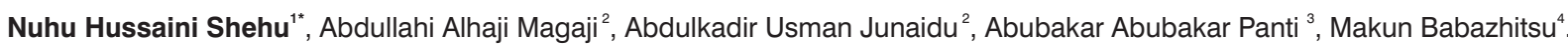

${ }^{1}$ Ministry of Animal Health, Husbandry and Fisheries, Birnin Kebbi, Kebbi State, Nigeria.

${ }^{2}$ Department of Public Health, Faculty of Veterinary Medicine, Usmanu Danfodiyo University, Sokoto, Nigeria.

${ }^{3}$ Department of Obstetrics and Gynaecology, Faculty of Clinical Sciences, College of Health

Sciences, Usmanu Danfodiyo University of Sokoto, Sokoto State. Nigeria.

${ }^{4}$ Department of Medical Microbiology and Parasitology, Faculty of Basic Clinical sciences,

College of Health Sciences, Usmanu Danfodiyo University of Sokoto, Sokoto State. Nigeria.

Corresponding Author:

Nuhu Hussaini Shehu

Ministry of Animal Health, Husbandry and

Fisheries, Birnin Kebbi, Kebbi State, Nigeria.

Email:nuhusaini084@gmail.com

Tel: +2348035075598

\begin{abstract}
:
Background: Toxoplasmosis is a protozoan infection caused by infection with the obligate intracellular protozoan parasite Toxoplasma gondii ( $T$. gondii). Several studies have been reported of high seroprevalence of this parasite from various hospitals in Nigeria.
\end{abstract}

Aim: The aim of this study was to determine the seroprevalence of toxoplasmosis among the pregnant women receiving antenatal care in Sir Yahaya Memorial Hospital, Birnin Kebbi.

Methodology: This was a cross sectional study conducted at SYMH Birnin kebbi in 2015 using indirect Enzyme Linked Immunosorbent Assay (ELISA).

Results: The overall seroprevalence of anti-Toxoplasma antibodies was $33.3 \%$. 9.7\% seropositivity was found at first trimester, $60.5 \%$ from second trimester and $29.8 \%$ from third trimester. Using a chi square logistic regression analysis, lack of education, lower age at pregnancy, and frequency of close contacts with cats were significantly associated with the prevalence of IgG antibodies.

Conclusion: Most primary infections during pregnancy are asymptomatic, congenital toxoplasmosis can have serious effects on the developing fetus. Screening for primary infection is problematic, primary prevention is the most logical method to lower the risk of congenital infection. There is also a need to educate women on the safe handling of cat litter during pregnancy.

Keywords: Birnin Kebbi, IgG, Pregnant women, Seroprevalence, Toxoplasma gondii

\section{Introduction:}

Toxoplasma gondii is an obligate intracellular protozoan parasite with a complex life cycle. This agent causes toxoplasmosis between humans and animals and is one of the most prevalent chronic infections, infecting one third of the globe population [1]. Infection due to Toxoplasma gondii is a worldwide zoonosis, the organism infects herbivorous, omnivorous and carnivorous animals, including birds [2,3]. T. gondii infects a large proportion of the world's population but uncommonly causes clinically significant disease.
Ninety percent of Toxoplasmosis infection is usually an asymptomatic in immunocompetent subjects, but often takes a severe and life-threatening course during pregnancy, in fetuses, ew born babies and in immunocompromised patients $[4,5]$.

Acute primary maternal toxoplasmosis if acquired during the first trimester of pregnancy can cause significant morbidity and mortality in developing foetuses [6]. The risk of congenital toxoplasmosis infection from a mother with primary toxoplasmosis increases during pregnancy, from $0 \%$ to $9 \%$ in the first 
Seroprevalence of Toxoplasmosis in Pregnant Women Attending Antenatal Care at Sir Yahaya Memorial Hospital, Birnin Kebbi, Northwestern Nigeria

trimester to $35 \%$ to $59 \%$ in the third trimester [7]. In most African countries, sufficient attention is yet to be given to toxoplasmosis [7].

Up to one third of the world's human population is estimated to be carrying a Toxoplasma infection [8]. In the United States, the overall age-adjusted Seroprevalence is $22.5 \%$, and $15 \%$ among women of childbearing age (15 to 44 years) [9]. Report from Africa, showed $34.1 \%$ in Sudan [1-10]. The overall Seroprevalence of anti-Toxoplasma antibodies was $45.5 \%$ in Cameroon [11] whereas a prevalence 68.4 [12] was found in Ethiopia. Some of the studies in Nigeria include; $29.1 \%$ prevalence in Zaria [13] .Lagos reported a prevalence of $32.8 \%$ [5]. Studies from Sokoto and Maiduguri reported prevalence of 27.7\% [14] and 48.9\% [15] respectively. Studies from Sokoto reported a prevalence of $7.0 \%$ in cats [16]. All these studies emphasize the need to sensitize pregnant women to the disease and its mode of transmission during their prenatal follow-up, in order to reduce the risk of first infection during their pregnancy[11].

\section{Materials and Methods}

\section{Study Area}

Birnin Kebbi, a city located in North-Western Nigeria lies between $12.45^{\circ} \mathrm{N}$ latitude and $4.2^{\circ} \mathrm{E}$ longitude. It is the capital city of Kebbi State and headquarters of the Gwandu Emirate.

The City is connected by road to Argungu $45 \mathrm{~km}$ Northeast, Jega $35 \mathrm{~km}$ Southeast and Bunza $45 \mathrm{~km}$ Southwest (Kebbi State, 2015). Based on the 2006 census the city has a population of 268, 620 (males 135,426 \& females 133,194), mostly Hausa and Fulani, with Islam as the major religion [17].

Sir Yahaya Memorial Hospital Birnin Kebbi is the study area. The hospital is a secondary health care institution in the metropolis and a referral centre within the state. It is over 290 capacity bedded facility with annual average of 200 to 220 patients' admission. It protocols and services are easily accessible, cheap and affordable.

\section{Study Design}

A cross sectional study using convenience sampling method was employed in this study. The sampling covered a period of two months (November to December, 2015).

\section{Ethical Consideration}

Ethical clearance was sought and obtained from Ethical Committee of Sir Yahaya Memorial Hospital, Birnin Kebbi, Kebbi State, before commencement of the study. The blood donors were adequately briefed that participation is voluntary. The purpose, benefit and their roles in the study was explained and the confidentiality of the information obtained was assured to them. Participants consent was obtained before the study was conducted.

\section{Study Population}

The study populations were the pregnant women attending Ante Natal Clinic at Sir Yahaya Memorial Hospital, Birnin Kebbi. enrolled by simple random sampling. A minimum sample size of 342 subjects was calculated for this study.

\section{Serological study}

Each participant in this study completed a structured questionnaire. This questionnaire contained simple questions about known risk factors of $T$. gondii exposure in addition to clinical and socio-demographic information. Blood samples were collected from each participant and centrifuged at $1200 \mathrm{rpm} / \mathrm{min}$ and the sera were separated into labelled vials and stored at $4^{\circ} \mathrm{C}$ and then tested for the presence of $T$. gondii antibodies using the indirect Enzyme Linked Immunosorbent Assay (ELISA) method and anti-Toxoplasma IgG (Nova Tec Immunodiagnostica) Germany.

\section{Results:}

Three hundred and forty-two pregnant women participated in this study. Twenty-five representing $7.3 \%$ were in first trimester, $200(58.5 \%)$ in second trimester and $117(34.2 \%)$ in third trimester. A total of 114 participants representing $33.3 \%$ tested positive for toxoplasma $\mathrm{IgG}$. On trimester distribution, 11 (9.7\%) were from first trimester, $69(60.5 \%)$ from second trimester and 34 (29.8\%) from third trimester as shown in Table 1. Infection was observed to be higher in pregnant women who had registered in the age category 30 years and below (34.0\%), whereas those in the age category above 30 years had prevalence of $28.9 \%$. In the educational level (western school), infection was slightly higher in women not educated (34.3\%) than those educated $(32.4 \%)$, also among the tribes, the infection was higher in other tribes $(38.2 \%)$ than the Hausa/Fulani (32.8\%) as shown in Table 2 . 
Seroprevalence of Toxoplasmosis in Pregnant Women Attending Antenatal Care at Sir Yahaya Memorial Hospital, Birnin Kebbi, Northwestern Nigeria

Table 1: logistic regression analysis of toxoplasmosis in pregnant women at different trimester attending ANC at sir yahaya memorial hospital, Birnin Kebbi $(n=114)$

\begin{tabular}{lcccc}
\hline Variable & $\begin{array}{l}\text { Prevalence } \\
(\%)\end{array}$ & P-value & OR & 95\% CI \\
\hline First trimester & $11(9.7)$ & Ref & NA & NA \\
Second trimester & $69(60.5)$ & 0.352 & 0.670 & $0.289-1.556$ \\
Third & $34(29.8)$ & 0.149 & 0.521 & $0.215-1.263$ \\
trimester & & & & \\
\hline
\end{tabular}

Level of significance $=0.05$

Table 2: Analysis of Socio-Demographic Factors for Toxoplasmosis in Pregnant Women Attending ANC at Sir Yahaya Memorial Hospital, Birnin Kebbi

\begin{tabular}{lllcccc}
\hline Risk factor & Response & $\begin{array}{c}\text { Prevalence } \\
(\%)\end{array}$ & $\begin{array}{c}\text { Chi-sq. } \\
\text { value }\end{array}$ & P-value & OR & $95 \%$ CI \\
\hline Age & $\leq 30$ years & $\begin{array}{c}101 / 297(34.0) \\
13 / 45(28.9)\end{array}$ & 0.461 & 0.497 & 0.788 & $0.396-1.568$ \\
& $>30$ years & Ref & 1.0 & NA \\
Educational & Educated & $57 / 176(32.4)$ & & Ref & 1.0 & NA \\
level & Not educated & $57 / 166(34.3)$ & 0.146 & 0.702 & 1.092 & $0.696-1.712$ \\
& & & & & & \\
Tribe & Hausa/Fulani & $101 / 308(32.8)$ & & Ref & 1.0 & NA \\
& Others & $13 / 34(38.2)$ & 0.408 & 0.523 & 1.269 & $0.611-2.637$
\end{tabular}

Level of significance $=0.05$, OR: Odds ratio, CI: Confidence interval, Reference value, NA: Not applicable

\section{Discussion:}

The prevalence of Toxoplasma $\operatorname{IgG}$ in this study was $33.3 \%$, this shows that the disease may be endemic in Birnin Kebbi town. However, there is variation with what was observed from some of the previous studies carried out in other parts of the country.

For instance, a prevalence rate of $27.7 \%$ in pregnant women in Sokoto was previously using Latex Agglutination test [18]. In Zaria, a prevalence of 29.1\% was recorded [13] and $48.9 \%$ in Maiduguri [19]. Prevalence of $40.8 \%$ and $32.8 \%$. were obtained in Lagos [5]. In Ibadan, overall prevalence rates of $75.4 \%$ and $80.5 \%$ of Toxoplasma antibody in pregnant and postpartum women were observed [20].

Surveys of Toxoplasmosis from other parts presented infection rates that were somehow consistent with this study. For instance in Tanzania, prevalence of 30.9\% [21] was recorded.

The women mostly affected were in the second trimester
$(60.5 \%)$, this may be connected with the fact that most of the women tend to shift their house hold chores to their subordinates as the pregnancy advances to third trimester. This shift in the infection was also seen in a previous study by Mombro and colleagues, who found that risk of congenital toxoplasmosis infection from a mother with primary toxoplasmosis increases during pregnancy, from $0 \%$ to $9 \%$ in the first trimester to $35 \%$ to $59 \%$ in the third trimester [6]. Fortunately, the later in pregnancy that congenital infection occurs, the less severe the consequences are to the fetus. It was deduced that $65.7 \%$ of the women screened did not attend western school and are complete house wives. All the women screened said they had no prior knowledge of the disease. This could explain the reason for high prevalence of toxoplasmosis in this study.

IgG antibody levels become detectable 1 to 2 weeks after infection and remain elevated indefinitely, while IgM antibody levels increase within days and usually remain elevated for 2 to 3 months [22]. However, IgM antibody 
Seroprevalence of Toxoplasmosis in Pregnant Women Attending Antenatal Care at Sir Yahaya Memorial Hospital, Birnin Kebbi, Northwestern Nigeria

levels can remain positive for more than 2 years in up to $27 \%$ of women when using ISAGA, making it difficult to pinpoint the timing of infection.[23] Thus, early detection of $\operatorname{IgG}$ in a woman at the beginning of pregnancy indicates prior infection and thus eliminates the risk of congenital transfer of tachyzoites.

\section{Conclusion}

Most primary infections during pregnancy are asymptomatic, congenital toxoplasmosis can have serious effects on the developing foetus. Screening for primary infection is problematic, primary prevention is the most logical method to lower the risk of congenital infection. There is also a need to educate women on the safe handling of cat litter during pregnancy.

\section{Acknowledgement:}

The authors acknowledge with sincere thanks the health professionals working in the Sir Yahaya Memorial Hospital, Birnin Kebbi for their cooperation during data collection. The participants who volunteered in this study are also acknowledged.

\section{Conflict of interest: none}

\section{References:}

1. de la Luz Galvan-Ramirez M, Troyo R, Roman S, Calvillo-Sanchez C, Bernal-Redondo R. A systematic review and meta-analysis of Toxoplasma gondii infection among the Mexican population. Parasites \& vectors. 2012;5(1):271.

2. Arko-Mensah J, Bosompem K, Canacoo E, Wastling J, Akanmori B. The seroprevalence of toxoplasmosis in pigs in Ghana. Acta Tropica. 2000;76(1):27-31.

3. Kravetz JD, Federman DG. Cat-associated zoonoses. Archives of Internal Medicine. 2002;162(17):1945-52.

4. Robert-Gangneux F, Yera H, D'Herve D, Guiguen C. Congenital toxoplasmosis after a preconceptional or periconceptional maternal infection. The Pediatric infectious disease journal. 2009;28(7):6601 .

5. Deji-Agboola A, Busari O, Osinupebi O, Amoo A. Seroprevalence of Toxoplasma gondii antibodies among pregnant women attending antenatal clinic of Federal Medical Center, Lagos, Nigeria. Int J Biol Med Res. 2011;2(4):1135-9.

6. Mombro M, Perathoner C, Leone A, Buttafuoco V, Zotti C, Lievre MA, et al. Congenital toxoplasmosis: assessment of risk to newborns in confirmed and uncertain maternal infection. European journal of pediatrics. 2003;162(10):703-6.

7. Wellington A, Oladipo O, Chimere O, Oladele T, Anunobi CC, Soyebi K. Congenital Toxoplasmosis: A Review of its Pathology, Immune Response and Current Treatment Options. Sierra Leone Journal of Biomedical Research. 2009;1(1):9-20.

8. Lindström I, Kaddu-Mulindwa DH, Kironde F, Lindh J. Prevalence of latent and reactivated Toxoplasma gondii parasites in HIV-patients from Uganda. Acta tropica. 2006;100(3):218-22.

9. Acha PN, Szyfres B. Zoonoses and communicable diseases common to man and animals: Pan American Health Org; 2003.

10. Elnahas A, Gerais AS, Elbashir MI, Eldien ES, Adam I. Toxoplasmosis in pregnant Sudanese women. Saudi medical journal. 2003;24(8):868-70.

11. Todjom FG, Tsapi EM, Gamago G, Vignoles P, Pone JW, Teukeng FD. Seroprevalence of toxoplasmosis and associated risk factors in pregnant women at the Protestant Hospital, Mbouo-Bandjoun, Cameroon. African Journal of Clinical and Experimental Microbiology. 2019;20(3):221-30.

12. Agmas B, Tesfaye R, Koye DN. Seroprevalence of Toxoplasma gondii infection and associated risk factors among pregnant women in Debre Tabor, Northwest Ethiopia. BMC research notes. $2015 ; 8(1): 107$.

13. Ishaku B, Ajogi I, Umoh JU, Lawal I, Randawa A. Seroprevalence and riskfactors for Toxoplasma gondii infection among antenatal women in Zaria, Nigeria. Res JMed Med Sci. 2009;4(2):483-8.

14. Alayande M, Edungbola L, Fabiyi J, Awosan K. Occurrence of antibody to Toxoplasma infection among pregnant women with obstetric histories and at different trimesters in Sokoto, Northwest Nigeria. American Journal of Research Communication. 2013;1(9):240-7.

15. Onadeko MO, Joynson D, Payne R, Francis J. The prevalence of toxoplasma antibodies in pregnant Nigerian women and the occurrence of stillbirth and congenital malformation. African journal of medicine and medical sciences. 1996;25(4):331-4.

16. Raji A, Magaji A, Bello M, Lawal M, Mamuda A, Yahaya M. Prevalence of gastrointestinal parasites of stray cats: a case study of two hospitals in Sokoto Metropolis, Sokoto, Nigeria. J Bacteriol Parasitol. 2013;4(175):2.

17. Kaoje IU, Dankani I, Ishiaku I. Site Suitability Analysis for Municipal Solid Waste Disposal in Birnin Kebbi, Nigeria. IOSR Journal of Humanities and Social Science (IOSR-JHSS). 2016;21(7):01-10.

18. Alayande M, Edungbola L, Fabiyi J, Awosan K, Babatunde S, Suleiman A, et al. Seroprevalence of Toxoplasma infection in stored sera of HIV individual in Sokoto, Nigeria. Afr J Microbiol Res. 2012;6:972-5.

19. Nasir IA, Aderinsayo AH, Mele HU, Aliyu MM. Prevalence and associated risk factors of Toxoplasma gondii antibodies among pregnant women attending Maiduguri teaching hospital, Nigeria. Journal of Medical Sciences. 2015;15(3):147.

20. Onadeko MO, Joynson D, Payne R. The prevalence of Toxoplasma infection among pregnant women in Ibadan, Nigeria. The Journal of tropical medicine and hygiene. 1992;95(2):143-5.

21. Mwambe B, Mshana SE, Kidenya BR, Massinde AN, Mazigo HD, Michael D, et al. Sero-prevalence and factors associated with Toxoplasma gondii infection among pregnant women attending antenatal care in Mwanza, Tanzania. Parasites \& vectors. $2013 ; 6(1): 222$.

22. Despommier D, Gwadz R. Parasitic Diseases 3rd edn. Parasite. 1995; 14:259-76.

23. Gras L, Gilbert R, Wallon M, Peyron F, Cortina-Borja M. Duration of the IgM response in women acquiring Toxoplasma gondii during pregnancy: implications for clinical practice and cross-sectional incidence studies. Epidemiology \& Infection. 2004;132(3):541-8. 